\title{
Edukasi Pengenalan Huruf Hijaiyah dengan Memanfaatkan Teknologi Augmented Reality
}

\author{
Fajar Septian', Bobi Agustian² \\ ${ }^{1,2}$ Teknik Informatika, Universitas Pamulang, Tangerang Selatan, Banten, Indonesia, 15417 \\ e-mail: ${ }^{1}$ dosen00677@unpam.ac.id, ${ }^{2}$ dosen00679@unpam.ac.id
}

Submitted Date: December $10^{\text {th }}, 2020$

Revised Date: January $01^{\text {st }}, 2021$

\author{
Reviewed Date: December $31^{\text {st }}, 2020$ \\ Accepted Date: January $05^{\text {th }}, 2021$
}

\begin{abstract}
Augmented Reality (AR) technology is the latest technology that provides opportunities for science and also has opportunities in the world of education, such as being able to provide and display $3 D$ objects, sound, video, and text objects. With this situation, AR technology has the opportunity to be used in the development of a medium to introduce hijaiyah letters, so that children will be more happy to learn it because of its attractive appearance and teachers or parents can more easily give lessons to their children. As for how to use it as follows: 1. The printed marker is placed on a flat surface or held, 2. The smartphone camera functions to scan the printed marker. If the marker is suitable and identified, the scanned marker will display the objects hijaiyah letters in $3 D$, 3. Students can understand and memorize the hijaiyah letters displayed from the marker.
\end{abstract}

Keywords: Hijaiyah; Augmented Reality; Marker; Technology

\begin{abstract}
Abstrak
Teknologi Augmented Reality (AR) merupakan teknologi terbaru yang peluang terhadap ilmu sains dan juga memiliki peluang dalam dunia pendidikan, seperti dapat memberikan dan menampilkan berupa objek 3D, suara, video, dan teks objek. Dengan keadaan ini, teknologi AR memiliki peluang untuk digunakan dalam pengembangan suatu media untuk mengenalkan huruf hijaiyah, sehingga anak akan lebih senang mempelajarinya karena tampilannya yang menarik dan guru atau orang tua dapat lebih mudah meberikan pelajaran terhadap anaknya. Adapun cara penggunaanya sebagai berikut:1. Marker yang sudah dicetak diletakan dipermukaan yang datar atau dipegang, 2. Kamera smartphone berfungsi untuk menscan hasil marker yag sudah dicetak, Jika marker sesuai dan teridentifikasi, maka marker yang discan akan menampilkan objek-objek huruf hijaiyah dalam bentuk 3D, 3. Siswa dapat memahami dan menghafal huruf hijaiyah yang ditampilkan dari marker.
\end{abstract}

Kata kunci: Hijaiyah; Augmented Reality; Marker; Teknologi

\section{Pendahuluan}

Teknologi informasi telah berkembang dengan pesat dan telah dimanfaatkan dalam berbagai bidang. Teknologi informasi ditujukan untuk membantu pekerjaan dengan menyediakan informasi dan melakukan berbagai tugas yang berhubungan dengan pengolahan informasi (Hanum \& Saifudin, 2019). Teknologi informasi dimanfaat di dunia pendidikan untuk membantu efektifitas dalam belajar, yaitu dengan meningkatkan kemudahan, memperbaiki visualisasi dan interaksi.
Dalam proses belajar dibutuhkan rangkaian kegiatan yang dirancang, dilaksanakan, sehingga tercapainnya tujuan proses belajar yang efektif dan inovatif yaitu disebut dengan pembelajaran. Dengan kata lain, peserta didik (siswa atau anakanak) melakukan pembelajara agar dapat belajar dengan baik. Hal yang mendasar yang harus diketahui dan dipahami dalam membaca al-qur'an adalah mengetahui Huruf hijaiyah dan tata cara membacanya. Oleh sebab itu dalam penelitian kali ini kita mempalahjari dan mengenal 29 huruf hijaiyah menggunakan teknologi AR yang di install ke smartphone. Dikarenakan huruf al-qur'an ditulis 
dengan bahasa Arab maka tentunya yang akan dipelajari terlebih dahulu adalah huruf-huruf hijiyah. Dengan tujuan agar aplikasi ini dapat menumbuhkan minat belajar dan ketertarikan secara visual dalam proses belajar huruf hijaiyah. Penelitian dilakukan di TK Kusuma Bangsa.

Batas Permasalahannya adalah:

a. Aplikasi ini menampilkan huruf-huruf hijaiyah dalam bentuk 3D.

b. Aplikasi ini hanya difokuskan penggunaan augmented Reality dalam mengenalkan huruf - huruf hijaiyah yang terdiri dari 1 (alif), ب (ba), ت (ta), ث (tsa), ج (jim), ح (ha), خ (kha), د (dal), ذ (dzal), ر (ra), j

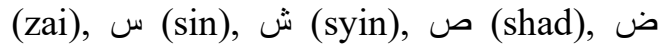
(dhad), b (tha), ظ (zha ${ }^{\text {ee }}$ ), ع (,ain), غ (ghain), ف (fa), ق ط (qaf), ك (kaf), J (lam), ? (mim), ن (nun), g (wau), 。 (ha), \& (hamzah), dan (ya).

c. Aplikasi hanya menunjukan cara penulisan pada markernya saja dan lebih menekankan pada aspek pengenalan dan mengingatkan Huruf Hijaiyah.

d. Metode waterfall namun tidak sampai pada pemeliharaan.

Penelitian ini bertujuan untuk membuat suatu rancang bangun aplikasi untuk pembelajaran huruf hijaiyah pada anak-anak TK di TK Kusuma Bangsa Bogor, diharapkan teknologi augmented reality pada aplikasi yang dibangun tersebut dapat membantu minat anak dan mengetahui huruf hijaiyah dengan memanfaatkan visualisasi secara 3D pada gambar agar menciptakan realitas nyata dalam proses pembelajaran.

\section{Metode Waterfal}

Dalam pengmpulan data, peneliti menggunakan metode obeservasi, metode wawancara, dan metode studi pustaka. Sedangkan dalam pengembangan sistem perangkat lunaknya, penulis menggunakan model waterfall. Dikarnakn Model Waterfall dalam pendekatannya alur dari perangkat lunak secara sekuensial atau berurutan yang dimulai dari menganalisa, mendesain, pengkodean, setelah itu pengujian dan tahap pendukung. Berikut adalah tahapan yang ada pada model waterfall adalah

a. Menganalisa Kebutuhan Sistem

Tahap ini menganalisa kebutuhan yaitu proses dalam pengumpulan data yang dibutuhkan secara intensif untuk menspesifikasikan kebutuhan perangkat lunak agar dapat dipahami seperti apa yang dibutuhkan oleh pengguna.

b. Desain

Di tahap ini yaitu proses yang berfokus pada desain dalam pembuatan program perangkat lunak termasuk strutur data, arsitektur perangkat lunak, representasi antar muka dan prosedur pengodean.

c. Implementasi Sistem

Tahapan ini merupakan tahap terakhir untuk pengimplemntasian aplikasi ini.

d. Pengujian Sistem

Setelah diimplentasikan maka tahap selanjutnya adalah pengujian (testing). Pengujian merupakan tahapan penting yang harus dilakukan untuk memberikan jaminan terhadap kualitas perangkat lunak yang dikembangkan (Muslimin, et al., 2020). Untuk menjamin kualitas sistem/aplikasi yang dikembangkan harus melalui tahap pengujian (Pratala, Asyer, Prayudi, \& Saifudin, 2020). Pengujian merupakan suatu rangkaian aktivitas yang terencana dan sistematis untuk menguji atau mengevaluasi kebenaran fungsi aplikasi berdasarkan desain kasus uji (test case) yang spesifik (Yulistina, Nurmala, Supriawan, Juni, \& Saifudin, 2020). Pengujian terhadap perangkat lunak sangat penting dilakukan dengan tujuan untuk memberikan jaminan kualitas perangkat lunak yang dihasilkan agar bebas dari terjadinya kesalahan (Debiyanti, Sutrisna, Budrio, Kamal, \& Yulianti, 2020).

e. Pendukung Sistem

Tahapan pendukung adalah tahapan mengulangi proses pengembangan mulai dari analisis spesifikasi sampai dengan pengujian sistem.

Perancangan aplikasi pengenalan Huruf Hijaiyah 3D dengan mengimplementasikan augmented Reality berbasis android dengan menggunakan $U M L$ sebagai salah satu cara agar mempermudah dalam pembuatan aplikasi. 


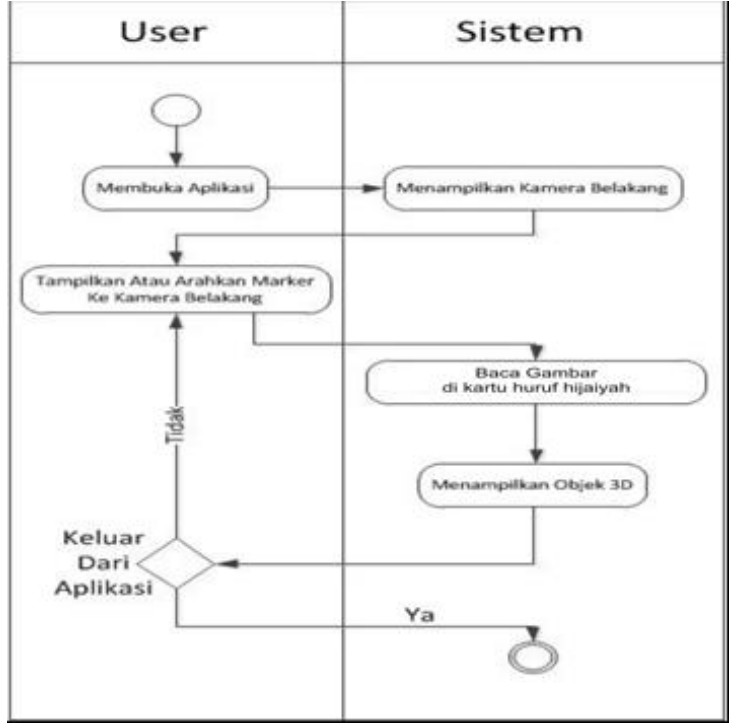

Gambar 1. Activity Diagram Implementasi Markerless Augmented Reality Dengan Metode Marker Based Tracking Berbasis Android

\section{Hasil dan Pembahasan}

a. Requiment Definition

Dalam tahapan ini, penulis mencari informasi mengenai kesulitan murid-murid dalam membaca huruf hijaiyah. Ada beberapa aspek yang menjadi murid-murid tidak cepat memahami dalam belajar membaca huruf hijaiyah :

1. Visualisasi yang menjadikan muridmurid tidak tertarik dalam membaca, seperti warna dan sebagainya.

2. Murid hanya belajar ketika jadwal sekolah, sehingga ketika dirumah muridmurid tidak mengulang kembali dalam membaca huruf-huruf hijaiyah.

b. Design Software

Use case diagram adalah sebuah metode dalam perancangan atau penggambaran suatu sistem yang digunakan untuk memberikan informasi mengenai pengembangan sistem yang sedang dibangun. Use case menjelaskan interaksi Actor dengan sistem yang dibangun.

c. Implementasi Unit

Berisi hasil sistem yang dirancang.

- Halaman Utama

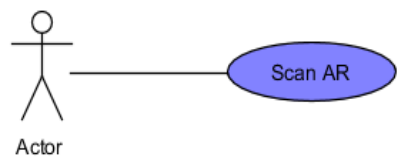

Gambar 2 Use Case Diagram

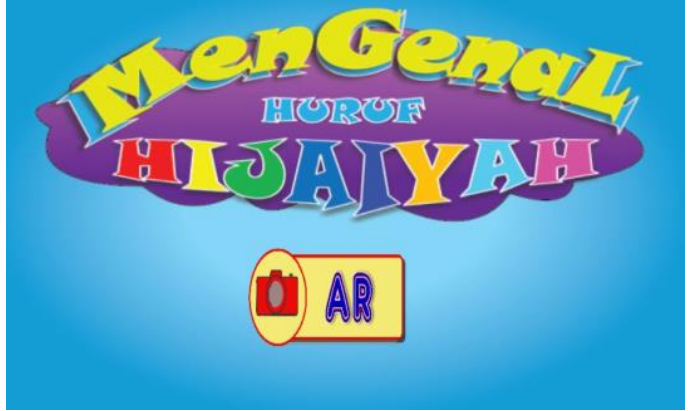

Gambar 3 Tampilan Aplikasi

- Marker untuk discan

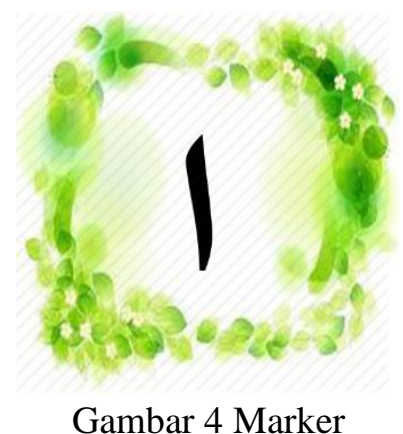

Tampilan yang akan tampil ketika marker sudah di scan.

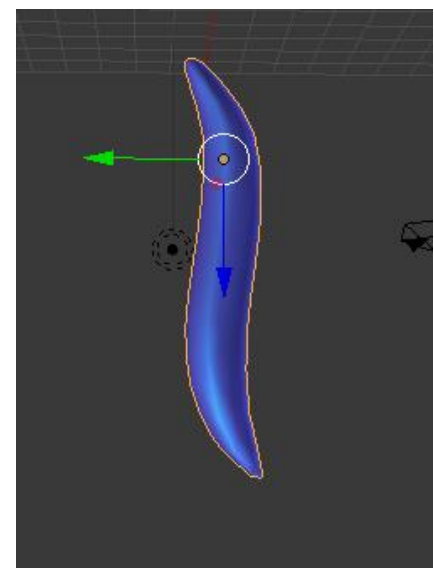

Gambar 5 Tampilan Alif 


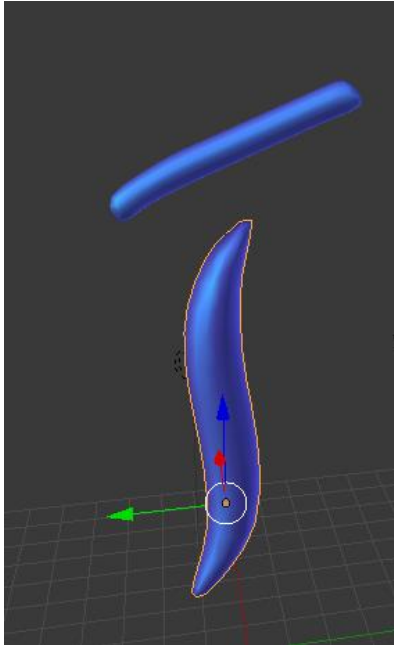

Gambar 6 Tampilan Alif fathah

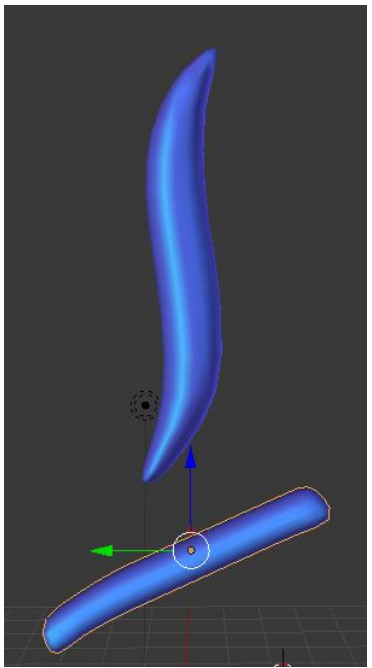

Gambar 7 Tampilan Alif

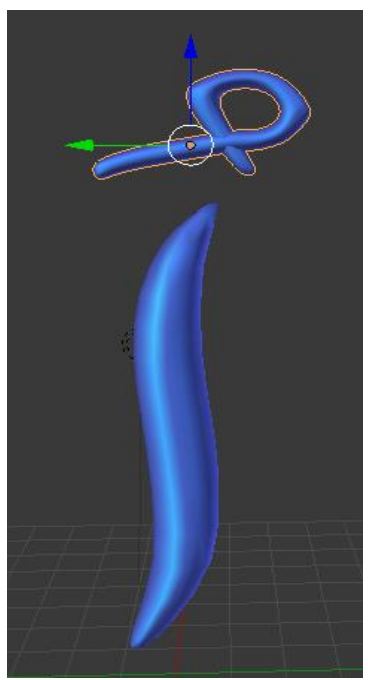

Gambar 8 Tampilan Alif Dhomah

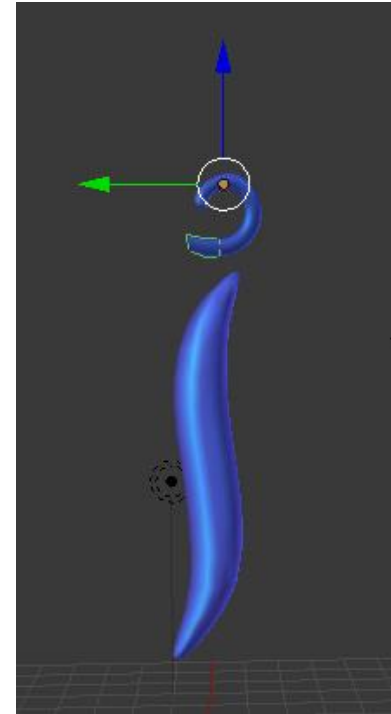

Gambar 9 Tampilan Alif Dhomah

\section{Kesimpulan}

Dengan adanya aplikasi ini, dapat membantu murid-murid belajar huruf hijaiyah lebih menarik dan dapat dipelajari di mana saja hanya dengan scan marker.

\section{Referensi}

Ableson, F., \& Sen, R. (2011). Android in action. Manning Publications Co.

Adami, Feby Zulham dan Cahyani Budihartanti. 2016. "Penerapan Teknologi Aumneted Reality Pada Media Pembelajaran Sistem Pencernaan Berbasis Android.” Jurnal Teknik Komputer AMIK BSI. 2(1): 123 .

Barfield, W. (Ed.). (2015). Fundamentals of wearable computers and augmented reality. CRC press.

Debiyanti, D., Sutrisna, S., Budrio, B., Kamal, A. K., \& Yulianti, Y. (2020). Pengujian Black Box pada Perangkat Lunak Sistem Penilaian Mahasiswa Menggunakan Teknik Boundary Value Analysis. Jurnal Informatika Universitas Pamulang, 5(2), 162-166. doi:10.32493/informatika.v5i2.5446

Dipura Atmaja, Nanda Juanda. 2018. "Pengembangan Aplikasi Media Pembelajaran Interaktif 3D tata surya Menggunakan Teknologi Augmented Reality Dengan Android." Seminar Nasional Sains dan Teknologi. p- ISSN : 2407 - 1846 eISSN : 2460 - 8416 Hal: $1-12$.

Hanum, W. S., \& Saifudin, A. (2019). Rancang Bangun Aplikasi Panduan Pariwisata di Kabupaten Banyuwangi Mobile Berbasis Android. Jurnal Teknologi Sistem Informasi dan Aplikasi, 2(2), 59-65. doi:10.32493/jtsi.v2i2.2798

Haryani, Prita dan Joko Triyono. 2017. “Augmented Reality (AR) Sebagai Teknologi Interaktif Dalam 
Pengenalan Benda Cagar Budaya Kepada Masyarakat.” Jurnal SIMETRIS. 8(2): 807-812.

Hashimi, S., Komatineni, S., \& MacLean, D. (2011). Pro Android 3. Apress.

Idrus, Ali dan Andreo Yudherta. 2016. "Pengembangan Augmented Reality Sebagai Media dalam Meningkatkan Pemahaman Teks Bacaan.” Jurnal Teknologi Pendidikan. 18(3): 140-155.J. K. Author, "Title of chapter in the book," in Title of His Published Book, xth ed. City of Publisher, Country if not USA: Abbrev. of Publisher, year, ch. $\mathrm{x}$, sec. $\mathrm{x}$, pp. $\mathrm{xxx}-\mathrm{xxx}$.

Kurniawan, Didik, Aristoteles dan Muhammad Fathan Kurniawan. 2015. "Augmented Reality (AR) Sebagai Teknologi Interaktif Dalam Pengenalan Benda Cagar Budaya Kepada Masyarakat." Jurnal Komputasi. 3(2): 136-143.

Mednieks, Z. R., Dornin, L., Meike, G. B., \& Nakamura, M. (2012). Programming android. " O'Reilly Media, Inc.".

Muslimin, D. B., Kusmanto, D., Amilia, K. F., Ariffin, M. S., Mardiana, S., \& Yulianti, Y. (2020). Pengujian Black Box pada Aplikasi Sistem Informasi Akademik Menggunakan Teknik
Equivalence Partitioning. Jurnal Informatika Universitas Pamulang, 5(1), 19-25. doi:10.32493/informatika.v5i1.3778

Ong, S. K., \& Nee, A. Y. C. (2013). Virtual and augmented reality applications in manufacturing. Springer Science \& Business Media.

Pratala, C. T., Asyer, E. M., Prayudi, I., \& Saifudin, A. (2020). Pengujian White Box pada Aplikasi Cash Flow Berbasis Android Menggunakan Teknik Basis Path. Jurnal Informatika Universitas Pamulang, 5(2), 111-119. doi:informatika.v5i2.4713

Yulistina, S. R., Nurmala, T., Supriawan, R. M., Juni, S. H., \& Saifudin, A. (2020). Penerapan Teknik Boundary Value Analysis untuk Pengujian Aplikasi Penjualan Menggunakan Metode Black Box Testing. Jurnal Informatika Universitas Pamulang, $5(2)$, 129-135. 